\title{
Cognitive Behavioural Therapy Perspectives to a Model on Social Phobia Based on Plato's Dialogue of Crito
}

\author{
By George Varvatsoulias*
}

In this paper, it is attempted an interdisciplinary approach, in cognitive-behavioural terms (CBT), between a model on social phobia and the book of Plato's "Crito". To conduct this study, I have devised an inventory based on the constructs of "virtue", "justice" and "legality" deriving from Crito's conversations with Socrates. I have employed correlational design to test these constructs against the social phobia model, and in particular against its constructs of "effortful processing", "inhibitory behaviours" and "feelings of shame and embarrassment". Correlations that were found between the three constructs from Plato's book were discussed in line to the respective ones of social phobia. Correlations were significant and positive though weak in direction. Correlations suggested associations between the constructs of Plato's book and the social phobia ones. Possibility for such associations and explanations, as to why could be applicable, were elaborated in the discussion section of this study.

Keywords: CBT, Justice, Shame, Social phobia, Virtue.

\section{Introduction}

Social phobia, otherwise called "social anxiety disorder", defines a fear about assumed and/or anticipatory situations of threat, which one considers as triggering worry against one's expected performance in the vicinity of others (Clark 1999). Situations, where fear can be elicited to support social phobia, are speaking in public, socialising and interacting with others, relationships, cooperation with others in the workplace, seeking and receiving advice from salient others, others' social expectations of oneself, etc. (Bögels et al. 2010). Social phobia is the thought process of negative appraisals that is elicited after fear has triggered thoughts of threat and worry (Craske et al. 2009).

Social phobia is considered as the main suffering condition for people of the middle classes (Gillis 2005). Numerous studies have been conducted to identify and discuss social anxiety in relation to issues of communication, fear of negative evaluation from others, fear or dread before the possibility of exposure to common social situations (Beck et al. 1985, Rapee 1995, Hofmann and Barlow 2002). Common idea of all those studies is that they point out to the same direction, which is anxiety foreshadowing expected failure. The aspect of "failure" represents a core appraisal to socially anxious individuals

\footnotetext{
* Module Leader and Lecturer, Newham College University Centre, UK.
} 
emerging from negative thinking, unhelpful feelings and avoidant behaviours (Wells and Papageorgiou 1998).

In the book of Crito, we find a number of different, yet similar, approaches to social phobia. Those refer to the way Crito anticipates them in relation to how others would see him, if he was not to "complete the task" of helping Socrates escape from prison (Crito 118: 44a). The book of Crito is one of a kind because it is a writing where social phobia is disguised by Crito's willfulness to "save" Socrates from death (Crito 120-123: 45a-46a). Crito's social phobia is disguised by the fact that "saving Socrates", Socrates would be able to carry on his work of inspiring people's minds with his ideas (Crito 121: 45c). I have chosen this writing because it is like a "predecessor" to modern CBT protocols regarding social phobia.

The protocol i am going to use emerged from the writings of Clark and Wells (1995) and Rapee and Heimberg (1997). Three phases are entertained in this protocol: the anticipatory phase, which relates to individual's interpretation of threat with regards to personal vulnerability; the situational exposure phase, in relation to given events in life, and how these affect oneself; the post-event processing phase, as to the interpretation of the social event and its outcome in the here and now (Clark and Beck 2011). This protocol will be compared against to the inventory I have devised and titled as: "A model on social phobia based on Plato's dialogue of Crito".

I came with the idea about this self-devised inventory having studied the protocol emerged from Clark and Wells' (1995) and Rapee and Heimberg's (1997) cognitive-behavioural framework. What this protocol is concerned about is to present social phobia in view to the anticipatory, situational exposure and post-event processing phases. These three phases are the main elements which demonstrate social phobia as an anxiety disorder.

Figure 1 suggests these three phases for social anxiety disorder has been recorded as follows:

Figure 1. Cognitive Model of Social Phobia

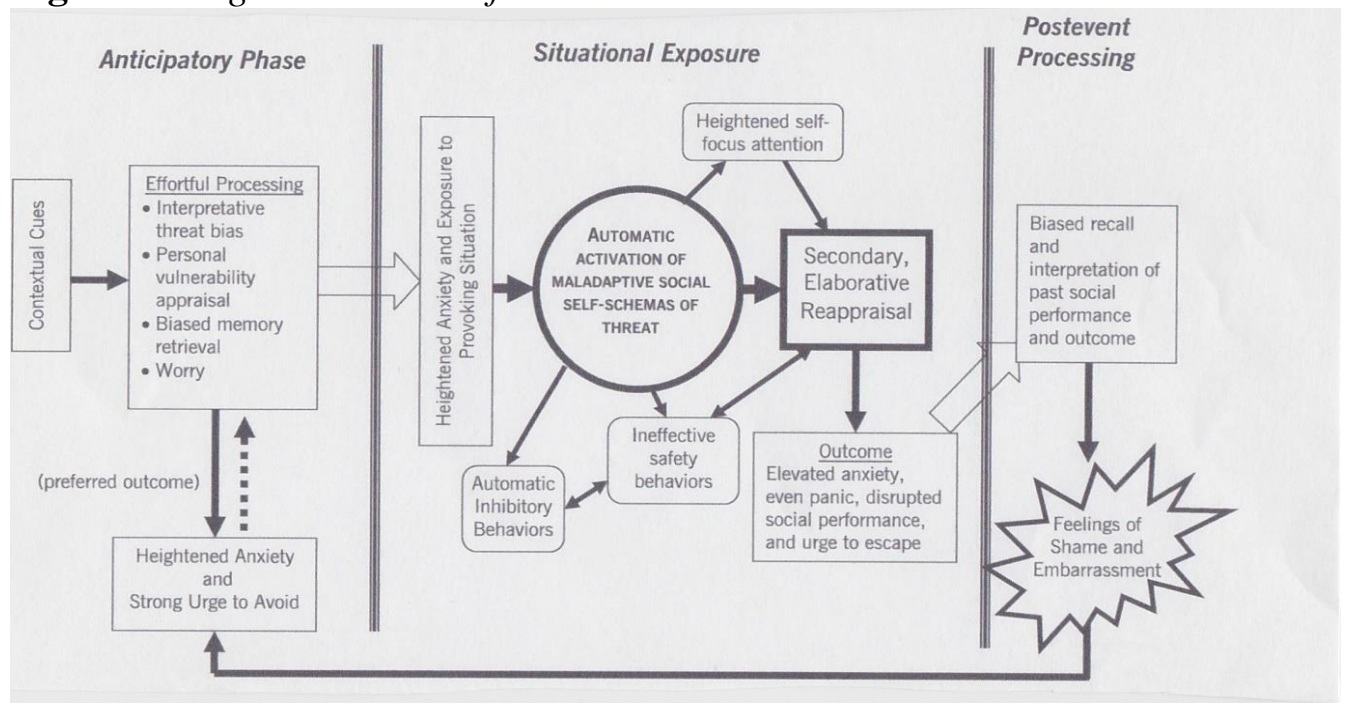

Source: Courtesy of Well's and Beck's 2011. 


\section{Anticipatory Phase}

The anticipatory phase underlines stimuli that are received from the environment through the senses which have to do with contextual experience, i.e. with experience that is the outcome of interplay between past and present circumstances associated to situations and/or events (Steiner 2002).

\section{Situational Exposure}

The situational exposure refers to how triggers eliciting the memory of circumstantial experiences become maladaptive when individuals interpret, feel, and act upon events in life that are regarded as predisposing factors to one's understanding of oneself; one's relationship to others; one's relationship to the social milieu (Morgan 2010).

\section{Post-event Processing}

Post-event processing is the maintenance cycle of maladaptive thinking, feeling and behaving. In this maintenance, assumptions and interpretations take place which relate to cognitive distortions of externalised and/or internalised importance, such as individuals considering in a generalised and black-andwhite thinking that circumstantial experience will be an ongoing eventful reality to one's here-and-now (Hofmann 2007).

In parallel to this framework for social anxiety, I have chosen Plato's dialogue of Crito for the reason it is a writing that underlines these three distinct phases in the experience of social anxiety disorder. In this text, we see Crito, a pupil of Socrates, who rushes into the jail where Socrates was kept, the very last night before Socrates's execution with the poison conium (hemlock) (Vetter 2004). In this dialogue, Crito is trying to convince Socrates to flee from jail and be free (Crito 121-123: 45d-46a). Socrates in his discussion with Crito tries to help Crito understand what is the real reason that his pupil wants him free (Crito 123-125: 46b-47a). As conversation advances, Socrates by using his famous open questioning helps Crito understand that the reason Crito wants him free, is not for the sake of Socrates but for the sake of himself (Crito 130148: $48 \mathrm{~d}-54 \mathrm{e})$. What we read in this text is that Crito wishes Socrates to flee because of Crito's worry and fear that if that doesn't happen Crito will be accused by others that he did nothing to save Socrates (Crito 118: 44a). In the text, there are unveiled assumptions and hypotheses referring to how Crito would feel about himself if Socrates was to drink the conium. In the end, it becomes apparent that Crito wants the safety of Socrates, so in the eyes of others not to be seen as a wealthy young man who though had the financial authority to save Socrates he didn't succeed so (Crito 118: 44c). What it is recorded in this dialogue is that Crito was looking after himself and his social affairs when he was trying to save Socrates, so that the name he had in the Athenian society not to fall short in the minds of others, if he couldn't convince 
Socrates to flee from prison. Crito's worry was that if Socrates would choose to die instead, Crito's reputation in the Athenian society would become defamed.

The choice of cognitive-behavioural therapy in this paper is because of five reasons:

1. It forms an evidence-based approach coming from cognitive science, which motivates theoretical and practical applications to client work relevant to:

a. the understanding of one's own condition and elaboration of cognitive processes based on one's explanation of experiences

b. offering clients not only a foundational learning method to their own problems, but how these can be overcome following alternative ways of thinking about themselves

2. Since cognitive-behavioural therapy employs as main element of approach Socratic Questioning, or the skill of Guided Discovery, as it is termed by Padesky (1993) and explained according to the CTS-R (Cognitive Therapy Skills - Revised) (James et al. 2001), all that leads back to the writings of Plato, one of which is the book of Crito, meaning that CBT is clearly defined as a psychotherapeutic practice according to the teaching of Socrates

3. The statements/questions selected to form the questionnaire, based on the book of Crito, are justified via the framework and protocol for social phobia in use in the present paper.

4. The use of correlation as a methodology for this empirical paper can provide interesting quantitative insights as to the use of variables to be associated, demonstrating that a parallel investigation of same terms has been the case for both Plato's century-old texts and modern CBT.

5. Finally, the way I employ century-old knowledge, as that is through the writings of the Ancient Greeks' Philosophy, I would like to motivate researchers to do the same so to discover modern psychotherapeutic interventions to human issues by thoroughly studying texts like the book of Crito. The empirical evidence I provide in this paper forms a new protocol for social phobia towards a better comprehension of this condition in CBT terms.

In this paper, I am employing Plato's dialogue of Crito to discuss the three phases of social anxiety/phobia disorder. The way I am trying to do so is by devising an inventory coming out of statements -both Socrates's and Crito'swhich are relevant and expressive to social phobia, comparing it to the above social anxiety framework. In such respect, my aim is to demonstrate that those three phases can be better explained if revised according to Socrates's conversations with Crito. My hypothesis to this study is co-relating the selfdevised inventory to the model of social phobia in terms of constituent parts of the dialogue explaining the three phases of the model. What this hypothesis will try to support will be the assumption that constructs, such as virtue, justice and legality, coming from Plato's book of Crito will be positively associated to 
the constructs of effortful processing, inhibitory behaviours and feelings of shame and embarrassment presented in the protocol of social phobia.

\section{Method}

Participants

115 participants were recruited for this study. Participants were a convenient sample. All were students at the Newham College University Centre, London, UK. They have voluntarily agreed to take part in my study. No compensation for their participation was offered. 21 were males and 94 females. Mean age and standard deviation were 39 and 11 respectively.

Design

The design will be correlational. The constructs to be associated will be virtue - the way that appears in Plato's text- against the effortful processing of the anticipatory phase; justice -the way that appears in Plato's text- against the inhibitory behaviours of the situational exposure phase; legality -the way that appears in Plato's text- against feelings of shame and embarrassment of the post-event processing phase.

I have selected two-tailed hypothesis, should a relationship be found to indicate that the increase or decrease of the constructs from Plato's text to assume increase or decrease of the constructs of the respective three phases. The explanation I provide for having chosen two-tailed hypothesis is that in social phobia protocols haven't so far been conducted any studies related to possible associations between constructs discussed in those protocols and constructs coming out of Plato's writings where conversations between Socrates and his pupils are observed.

\section{Tools/Measures}

The self devised inventory titled "A model on social phobia based on Plato's dialogue of Crito" (Appendix)

\section{Procedure}

The main scope of this study is to question whether the protocol on social phobia -as that has been suggested and developed according to Clark and Wells' (1995) and Rapee and Heimberg's (1997) approach- could be revised in view to the self-devised inventory on social phobia I have developed using Crito's dialogue with Socrates. Participants were administered the questionnaires, but before completing them they were explained the purpose of the study as this is outlined in the introduction. The ideas of virtue, justice and legality were discussed in view to the present inventory. Respondents were also 
explained how these three ideas are understood in Plato's text and what is the importance of the writing for the understanding of social phobia. Recruiters were also presented with the rationale how the ideas of virtue, justice and legality can be related to personal efforts, inhibitions and feelings. Examples, I have used to assist participants comprehend that rationale, followed discussion we had in class about social phobia in cognitive-behavioural terms. What I have done to discuss correlations in this study was to choose statements from Plato's text according to the ideas of virtue, justice and legality. These ideas were applied to the statements as follows: 1=virtue; $2=$ virtue; $3=$ virtue; 4=justice; 5=legality/justice; 6=justice; 7=justice/legality; 8=justice/legality; $9=$ virtue; $10=$ justice; $11=$ virtue; $12=$ legality. Before administering this selfdevised inventory I have pilot-studied it with another 20 participants so to consider reliability issues as to its statements. After scores were collected from both the pilot and the main study, they were inserted to the SPSS for data analysis.

Figure 2. Correlational Diagram

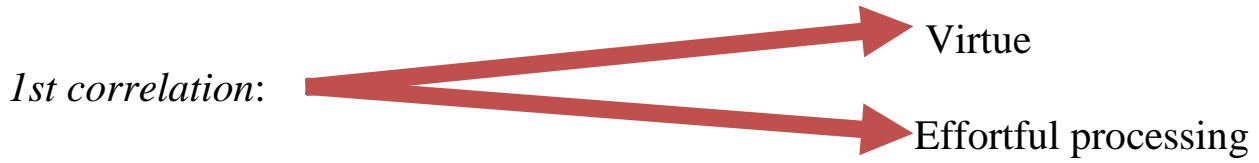

Rationale for 1st correlation: The more virtue increases the more effortful processing should increase as well -in view to social phobia

2nd correlation:

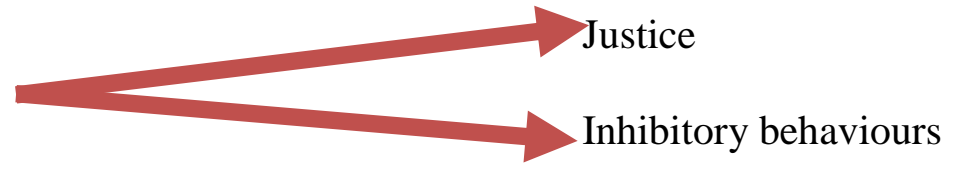

Rationale for 2nd correlation: The more justice increases the more inhibitory behaviours should increase too -in view to social phobia

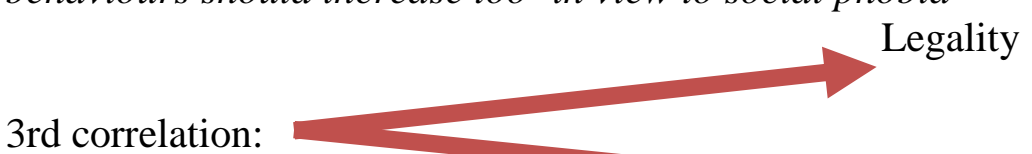

3rd correlation:

Feelings of shame and embarrassment

Rationale for 3rd correlation: The more legality increases the more feelings of shame and embarrassment should increase too in view to social phobia

\section{Results}

Table 1. Pilot Study-Reliability Statistics

\begin{tabular}{|c|c|c|}
\hline Cronbach's $\alpha$ & $\begin{array}{c}\text { Cronbach's } \alpha \text { based on } \\
\text { Standardised Items }\end{array}$ & N of Items \\
\hline .563 & .643 & 12 \\
\hline
\end{tabular}


For statement no. 09 of the inventory there is a strong indication that it is not a consistent part of the scale -correlation is very low $(.021) ; R^{2}$ is also low (.51). Perhaps, this item could be an indicator for the statement to be deleted or change.

Table 2. Descriptive Statistics

\begin{tabular}{|c|c|c|c|c|}
\hline Gender & Frequency & Age & Mean & $\begin{array}{c}\text { Standard } \\
\text { Deviation }\end{array}$ \\
\hline Males & 21 & 20 & 39 & 11 \\
\hline Females & 94 & 61 & & \\
\hline $\boldsymbol{N}$ & 115 & \multicolumn{2}{|}{} \\
\hline
\end{tabular}

$M=39, S D=11$

Table 3. Inferential Statistics

\begin{tabular}{|c|c|c|}
\hline Correlations & Pearson's $\boldsymbol{r}$ & $\boldsymbol{p}$ \\
\hline Virtue-Justice & .403 & .000 \\
\hline Justice-Legality & .309 & .001 \\
\hline Virtue-Legality & .250 & .007 \\
\hline $\boldsymbol{N}$ of cases & 115 & \\
\hline \multicolumn{2}{|r|}{}
\end{tabular}

- There was a significant positive correlation between virtue and justice ( $r=.403, N=115, p<0.01,2$-tailed). It is a weak correlation because only $16 \%$ of the variance is explained.

- There was a significant positive correlation between justice and legality ( $r=.309, N=115, p<0.01$, 2-tailed). It is also a weak correlation because only $10 \%$ of the variance is explained.

- There was a significant positive correlation between virtue and legality ( $r=.250, N=115, p<0.01,2$-tailed). However, again a weak correlation is found because only $10 \%$ of the variance is explained.

\section{Discussion}

Significant and positive correlations were found between constructs deriving from Plato's book of Crito. What was found was that virtue and justice in the book of Crito were significantly and positively related together, though in a weak association. The same direction and association were found between the constructs of justice and legality and virtue and legality. Constructs, those correlations to be discussed against, were effortful processing, inhibitory behaviours and feelings of shame and embarrassment, all representing the anticipatory, situational exposure and post-event processing phases respectively.

The hypothesis, as stated in the introduction of this study, assumed that the constructs of virtue, justice and legality could be respectively associated to the constructs of effortful processing, inhibitory behaviours and feelings of shame and embarrassment. To discuss possible associations, having found significant 
and positive correlations between the constructs of Plato's Crito, we could look to the exercise of "virtue" and how that might relate to "inhibitory behaviours" and "feelings of shame and embarrassment".

In looking at the anticipatory phase, "effortful processing" explains socially phobic issues related to "threat", "personal vulnerability" and "worry". Exercise of virtue obliges one towards effortful processing of elements to be satisfied, such as one to be a good citizen so to be accepted from others. In many cases, however, such as in the example, virtue can become a selffulfilling prophecy, which cannot be satisfied, leading one's effortful processing in decline. If effortful processing is in decline, virtue cannot prove one as just individual to the effect one to start worrying and thinking one is vulnerable to others' considerations against him/herself, giving rise thus to the aspect of threat before assumed feared situations (Ouimet et al. 2009). One by considering that one's "virtue" is no longer regarded as one's personal attribute in a social milieu, in order to compensate against his or her negative thinking, may contemplate to harbour "inhibitory behaviours" via avoiding social situations appraised to convey characteristics of threat, affective vulnerability and worry (Gorlin and Teachman 2014).

The way inhibitory behaviours can operate in a case of such an individual, could relate to ideas of justice, such as telling lies, so the individual not to be disclosed, to the effect one to suppressing self-knowledge that is beneficial for one's development regarding personal fairness and honesty when with other people. To consider inhibitory behaviours, according to the situational exposure phase, the individual elaborates more thoughts of threat in line with maladaptive social schemas related mostly to personal performance (PintoGouveia et al. 2006). Example: if an individual considers oneself as unable to perform before others, such as talking in the presence of them, justice can be the outcome of self-focus attention, whereby one condemns oneself for his or her inability to communicate and interact (Spurr and Stopa 2002).

It's easy now to understand, how feelings of shame and embarrassment could relate to one's difficulty to communicate and interact. One by having experienced thoughts of worry and threat, and then inhibiting actions because of such thinking, one can now experience feelings of shame and embarrassment remembering that in social performance terms one didn't perform well (McGregor and Elliot 2005). Feelings of shame and embarrassment refer to the emotional processing of a so-called "virtuous" and "just" self (Tangney et al. 2007). Example: If one's effortful processing has fallen apart, one may consider it is difficult to be "just" and "legal", i.e. to be honest and truthful as to what one hasn't achieved, to the outcome to be feeling shameful and embarrassed. Shame and embarrassment are the emotions to be felt when one is in the vicinity of salient, less salient, or non-salient others, thereby the avoidance and continuation of social phobia as an escape choice in one's life (Henderson et al. 2014).

"Virtue", "justice" and "legality" relate to the aspect of social phobia in terms of performance, acceptance from others, lack of tolerating thoughts of rejection, difficulty in dealing with others' assumed considerations about one's 
behaviours etc (Brook and Schmidt 2008). These constructs explain that social phobia in Plato's book relates also to the fact that the lack of assuming personal responsibility is another indicator that an individual finds difficult to accept. That means, one doesn't want to be in the wrong, or subject to the wrongness of others and therefore not standing self-distress regarding his or her self-focus expectation(s) to be at the centre of others' attention (Schultz and Heimberg 2008). In such a case, one will regard oneself to be a failure due to the situational exposure one considers that was brought about as far as one's performance is concerned. In thinking of oneself as thus, one can easily feel shame and embarrassment if one's views about oneself are anticipated as not having been satisfied, such as Crito's self-consideration that he will be harshly judged by others if he fails to save Socrates, in case his master finally drinks the conium (Irvine 2008).

In finalising the above discussions, according to the cognitive-behavioural framework -as that appears in Plato's work of Crito- the perceived audience, where the whole thinking process of Crito's takes place is the city of Athens and its citizens. There, Crito allocates preferences of attention to his person through ideas how others would see him, if he was not to save Socrates. That kind of understanding is seen by Crito as a perceived internal cue regarding others' consideration of his person in his relationship to Socrates. In Crito's mind, assumed appraisals of Athenian citizens, as to his person, relate to the aspects of virtue (how good has he been in his relationship to Socrates?); justice (how honest is what he does to save Socrates in the eyes of his fellow citizens?); and legality (how legal is to do that going against the laws of the city?). All these three ideas are regarded by Crito as self-focused goals how others would think of him, if he was to succeed or fail to save Socrates. The way Crito understands himself in the social environment relates to the fact that salient others influence the way he sees himself in terms of living up to a selfimage that can prove him both a good pupil of Socrates as well as a good citizen of the city.

In trying a diagram to depict what I have outlined in this paragraph with regards to Crito's social phobia (see Figure 3).

\section{Strengths and Limitations}

In coming to the end of the discussion, I would like to state strengths and limitations which on one hand provide insights to the development of this topic, and on the other offer alternatives how the same study could be replicated to forward the theoretical and empirical premises outlined in this subject-matter.

\section{$\underline{\text { Strengths }}$}

One of the main strengths in this study is that it focuses on the interdisciplinary perspective, Socratic dialogue writings to be associated with mental conditions, such as social phobia. So far, there hasn't been attempted in 
CBT a correlation of protocols in a parallel consideration to philosophical texts, such as the book of Crito. What has been attempted in this interdisciplinary perspective was to try Socratic dialogue texts in view to current cognitive behavioural ideas, such as that of social phobia. Another strength is that in this attempt, there have been taken into account premises, such as "virtue", "justice" and "legality", which could introduce a dialogue between current CBT approaches and Socratic ideas. Though, my attempt is far from complete, I am confident that I have provided some insights how such interdisciplinary discussion might carry on.

Figure 3. A Cognitive Behavioural Protocol on Social Phobia Based on Socrates's Conversations with Crito
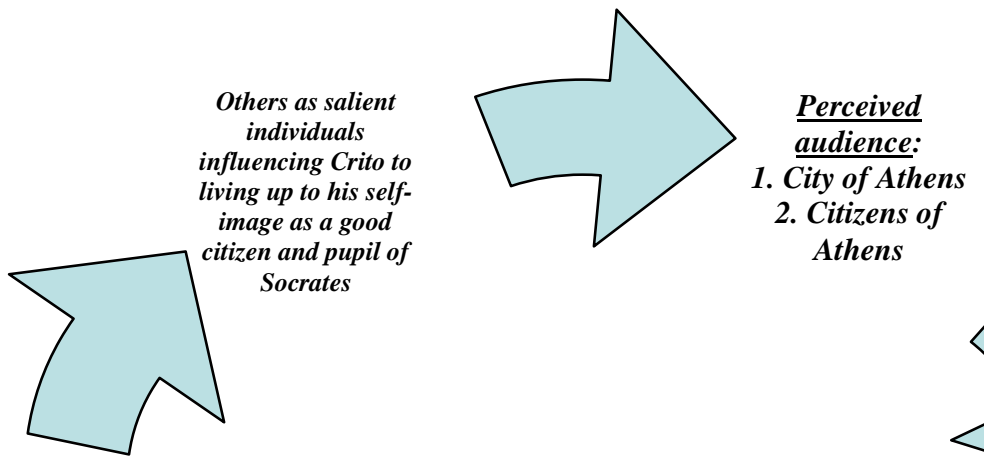
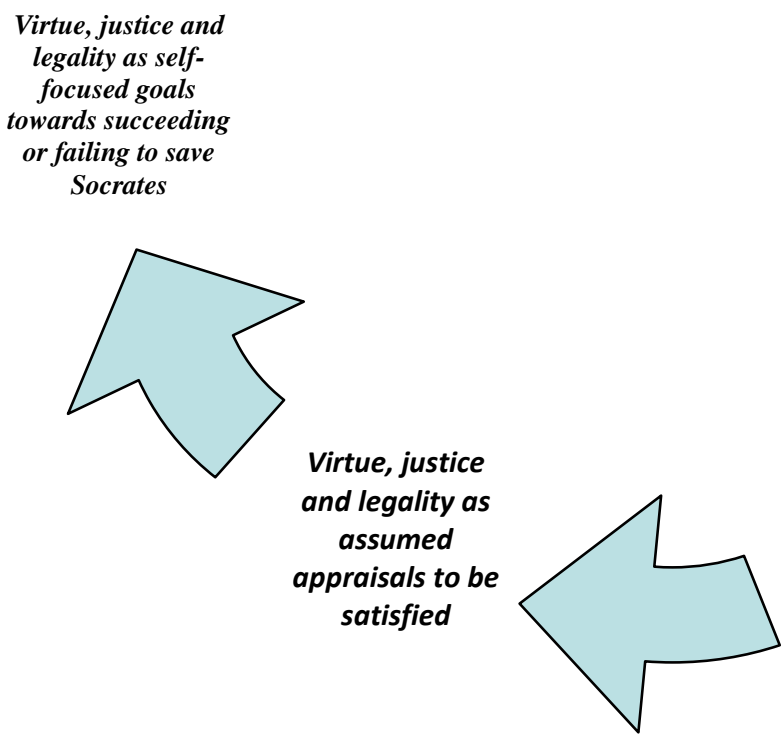

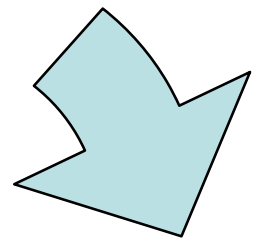

Crito's preference of attention: Others' thoughts if he was not to save Socrates

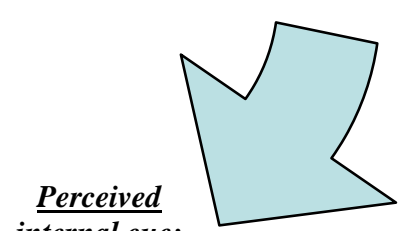

Socrates

\section{$\underline{\text { Limitations }}$}

One of the main limitations in this study is that I have co-related ideas coming out solely from Plato's book of Crito. The associations I attempted to do between these ideas and ideas from the social phobia protocol were suggestions how the self-devised inventory could be understood if that was to be taken over as a paradigm for social phobia and be further developed. What 
this limitation shows is that if I was to devise a second inventory based on specific social phobia aspects, such as those of "effortful processing", "inhibitory behaviours" and "feelings of shame and embarrassment", correlations to Plato's book could probably be more significant (in Pearson's $r$ terms) and possibly strong (as to the direction of correlation). One other limitation is that I could re-conduct the pilot study with same or different participants to see whether by excluding the item 09 , reliability could be more consistent.

\section{Conclusions}

In studying Plato's dialogue of Crito, and after conducting the correlations, I come to the conclusion that Clark and Wells' (1995) and Rapee and Heimberg's (1997) framework on social phobia could be better advanced as a treatment protocol if the aspects of effortful processing, inhibitory behaviours and feelings of shame and embarrassment were to be elaborated in terms of the constructs of virtue, justice and legality.

The reason for such advancement of the former aspects lies to the fact that the anticipatory, situational exposure and post-event processing phases take place as distinct features to the social anxiety disorder. These phases operate distinctively due to the cognitive processing of one's maladaptive understanding regarding the exercise of virtues, the application of justice and the presence of legality in interpersonal and social relationships.

The effort I have spent in conducting this study, certainly doesn't stop here. Results and findings of it though appear not so relevant as to the correlations I have made, they nevertheless point to the direction that Socratic texts, if were to be included in current CBT protocols, would probably better explain interventions so treatments to be met. In writing that, I do mean that Socratic texts need to have an effective participation in the whereabouts of modern CBT, in view to enhance its theoretical and practical endeavours towards assisting contemporary individuals in their here-and-now understanding of themselves.

\section{References}

Beck AT, Emery G, Greenberg RL (1985) Anxiety disorders and phobias: A cognitive perspective. New York, NY: Basic Books.

Bögels SM, Alden L, Beidel DC, Clark LA, Pine DS, Stein MB, Vancken M (2010) Social anxiety disorder: Questions and answers for the DSM-V. Depression and Anxiety, 27 (January): 168-181. doi= http://doi.acm.org/10.1002/da.20670.

Brook CA, Schmidt LA (2008) Social anxiety disorder: A review of environmental risk factors. Neuropsychiatric Disease and Treatment, 4(1): 123-143. doi= http:// PMID:18728768 [PubMed]/PMCID:PMC2515922. 
Clark DM (1999) Anxiety disorders: why they persist and how to treat them. Behaviour Research and Therapy 37: 5-27. doi= http://PII:S0005-7967(99)000 48- 0 .

Clark DM, Beck AT (2011) Cognitive therapy of anxiety disorders: Science and practice. London, UK: The Guilford Press.

Clark DM, Wells A (1995) A cognitive model of social phobia. In Social phobia: Diagnosis, Assessment and Treatment, RG Heimberg, MR Liebowitz, DA Hope, FR Schneier (Eds), 69-93. New York, NY: Guilford Press.

Craske MG, Rauch SL, Ursano R, Prenoreau J, Pine DS, Zinbarg RE (2009) What is an anxiety disorder? Depression and Anxiety 26 (September): 1066-1085. doi= http://doi.acm.org/10.1002/da.20633.

Crito (1885) Translated with comments and annotations by Louis Dyer,115-148. Boston, USA: The Athenaeum Press, Ginn and Company Proprietors.

Gillis V (2005) Raising the "meritocracy" parenting and the individualisation of social class. Sociology 39(5): 835-853. doi= http://soc.sagepub.com/cgi/content/refs/39/ 5/835/ 1177/0038038505058368.

Gorlin EI, Teachman BA (2014) Inhibitory control as moderator of threat-related interference biases in social anxiety. Cognition and Emotion. doi= http://dx. doi.org/10.1080/02699931.2014.931275.

Henderson L, Gilbert P, Zimbardo P (2014) Shyness, social anxiety, and social phobia. Social Anxiety (May): 95-115. doi= http://doi.acm.org/10.1016/B978-012-394427-6.

Hofmann SG, Barlow DH (2002) Social phobia (social anxiety disorder). In Anxiety and its disorders: The nature and treatment of anxiety and panic, DH Barlow (Ed), 454-476. New York, NY: Guilford Press.

Hofmann SG (2007) Cognitive factors that maintain social anxiety disorder: a comprehensive model and its treatment implications. Cognitive Behavior Therapy 36(4): 193-209. doi= 10.1080/16506070701421313.

Irvin AD (2008) Apology, Crito, and Phaedo. Toronto, Canada: University of Toronto Press.

James IA, Blackburn IM, Reichelt FK (2001) Manual of the revised cognitive therapy scale $(C T S-R)$. Newcastle Cognitive and Behavioural Therapies Centre and the University of Newcastle Upon Tyne, UK.

McGregor HA, Elliot AJ (2005) The shame of failure: Examining the link between fear of failure and shame. Personality and Social Psychology Bulletin 31(2): 218-231. doi= http://doi.acm.org/10.1177/0146167204271420.

Morgan J (2010) Autobiographical memory biases in social anxiety. Clinical Psychology Review 30 (April): 288-297. doi= http://doi.acm.org/10.1016/j.cpr.2009.12.003.

Ouimet AJ, Gawronski B, Dozois DJA (2009) Cognitive vulnerability to anxiety: A review and an integrative model. Clinical Psychology Review, 29(6): 456-470. doi= http://doi.acm.org/10.1016/j.cpr.2009.05004.

Padesky CA (1993, September 24) Socratic questioning: Changing minds or guided discovery? Keynote address delivered at the European congress of Behavioral and Cognitive Therapies, London, 1-6.

Pinto-Gouveia J, Castilho P, Galhardo A, Cunha M (2006) Early maladaptive schemas and social phobia. Cognitive Therapy Research 30 (June): 571-584. doi= http://doi. acm.org/10.1007/s10608-006-9027-8.

Rapee RM (1995) Descriptive psychopathology of social phobia. In Social phobia: Diagnosis, Assessment, and Treatment, RG Heimberg, MR Liebowitz, DA Hope, FR Schneier (Eds), 41-66. New York, NY: Guilford Press. 
Rapee RM, Heimberg RG (1997) A cognitive-behavioral model of anxiety in social phobia. Behaviour Research and Therapy 35 (August): 741-756. doi= http://PII: S0005-7967(97)00022-3.

Schultz LT, Heimberg RG (2008) Attentional focus in social anxiety disorder: potential for interactive processes. Clinical Psychology Review 28(7): 1206-1221. doi= http:// doi.acm.org/10.1016/j.cpr.2008.04.003.

Steiner T (2002) The biology of fear- and anxiety-related behaviours. Dialogues in Clinical Neuroscience, 4(3): 231-249.

Spurr JM, Stopa L (2002) Self-focused attention in social phobia and social anxiety. Clinical Psychology Review 22 (February): 947-975. doi= http://PII:S02727358(02)00107-1.

Tangney JP, Stuewig J, Mashek D (2007) Moral emotions and moral behavior. Annual Review of Psychology 58 (April): 345-372. doi= http://doi.acm.org/10.1146/annu rev.psych.56.091103.070145.

Vetter J (2004) Poison hemlock (Conium Maculatum L.). Food and Chemical Toxicology 42: 1373-1382. doi= http://doi.acm.org/10.1016/j.fct.2004.04.009.

Wells A, Papageorgiou C (1998) Social phobia: Effects of external attention anxiety, negative beliefs, and perspective taking. Behavior Therapy 29(3): 357-370. doi= http://doi.acm.org/10.1016/S0005-7894(98)80037-3. 


\section{Appendix}

\section{'A model on social phobia based on Plato's dialogue of Crito' (Please, circle your choice on each of the following statements)}

Gender:

1. "I appear to value my riches more, instead of my friends"

\section{Age:}

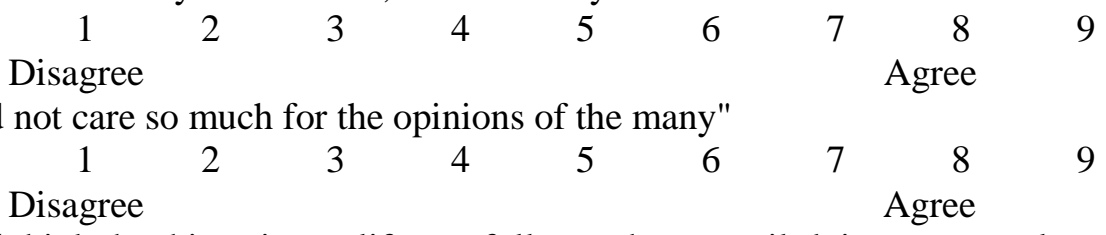

3. "I should think the things in my life carefully, so that no evil-doing may result to disgracefulness"

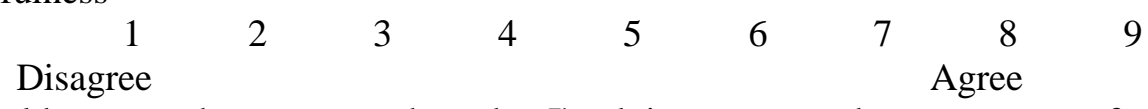

4. "I should recur to the argument that what I'm doing now may be an outcome of what I have done in the past"

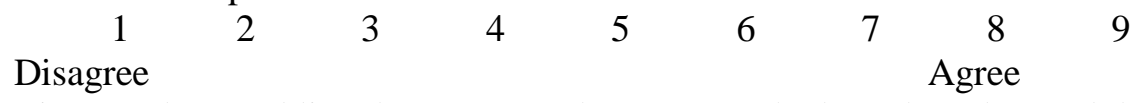

5. "To stay in one place and live there, means that I accept the law, the rules, and the principles of a given society"

$\begin{array}{ccccccccc}1 & 2 & 3 & 4 & 5 & 6 & 7 & 8 & 9 \\ \text { Disagree } & & & & & & & \text { Agree } & \end{array}$

6. "We need not to be anxious about living, but about living well"

$\begin{array}{cccccccccc}1 & 2 & 3 & 4 & 5 & 6 & 7 & 8 & 9 \\ \text { Disagree } & & & & & & & \text { Agree } & \end{array}$

7. "If the beginning of an inquiry is well structured, then questions are more easily answered with regards to social issues"

$\begin{array}{cccccccccc}1 & 2 & 3 & 4 & 5 & 6 & 7 & 8 & 9 \\ \text { Disagree } & & & & & & & \text { Agree } & \end{array}$

8. "Is it right one to do evil in return, when one has been evilly treated?"

\begin{tabular}{cccccccccc}
1 & 2 & 3 & 4 & 5 & 6 & 7 & 8 & 9 \\
Disagree & & & & & \multicolumn{4}{cl}{ Agree } &
\end{tabular}

9. "Others' opinions affect us from the time we pay too much attention to them"
Disagree
23
34
56
$7 \quad 8$
Agree

10. "Considerations and sayings of other people, in reality belong to multitudes of sophisms, which rashly try to resolve problems, and in effect cause harm instead"
1
23
45
$6 \quad 7$
89
Disagree
Agree

11. "To employ means that suit me, such as paying money to people to do me favours, it is not a proper thing to do"

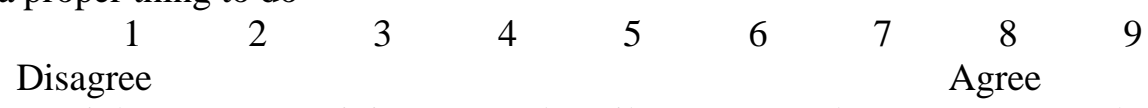

12. "It is not right to return an injury, or to do evil to any man, however one may have suffered from another"

$\begin{array}{rrrrrrrrr}1 & 2 & 3 & 4 & 5 & 6 & 7 & 8 & 9 \\ \text { Disagree } & & & & & & & \text { Agree } & \end{array}$

